\title{
Application of Linear Optimization on Parameters of 3D FDM Print
}

\author{
Oskar ZEMCIK, Josef SEDLAK
}

\begin{abstract}
Nowadays, a fused deposition modelling (also called "FDM") belongs to one of the most widespread additive methods of 3D print. It allows producing both models for functional verification or casts and functional components. The main advantage of this technology is an option to produce complex components of a difficult shape independent of their outer and inner surfaces. Moreover, this mentioned technology brings the decreasing of production costs in comparison with the other well-known additive methods. The final quality of a product depends on the used material and on technological conditions at the same time. The number of parameters and limits of the complete printing process is enormous. The choice of the individual parameters by a trial-and-error procedure is very time-consuming. Therefore, a use of linear optimization for finding of optimal values of chosen print parameters can be offered. For forming of the required procedures, it seems to be necessary to choose structural variables, find an appropriate objective function and deduce properly limiting conditions in a linear shape, which relates to a linear measurement. The final solution enables, on the basis of the selected initial conditions, to choose optimal parameters of the 3D print for a given material and production equipment in a relatively short period.
\end{abstract}

Keywords: 3D Print; FDM; Fused Deposition Modelling; linear programming; minimal costs; optimization

\section{INTRODUCTION}

An additive technology called the Fused Deposition Modelling (abbreviated FDM) [1] is sometimes called Fused Filament Fabrication (abbreviated FFF), but it is essentially the same technology [2]. The technology enables to process a huge amount of materials, especially thermoplastics or materials with a technically reachable viscous liquid phase. Curable materials (modelling clay, concrete) or applications of impurities forming composites are also usable. Nevertheless, the most widespread is the utilization of thermoplastics as acrylonitrile butadiene styrene (ABS), polylactic acid (PLA), high impact polystyrene (HIPS), polyamide (PA), polyethylene terephthalate (PET), etc. $[3,2]$. Besides the use of this method in biomedicine or robotics [4], in last few years, the evaluation of an influence of individual technological parameters on product qualities has been becoming a priority [3, 5-13], along with the influence of the 3D print on a working environment and therefore on human health [14-16].

Even though the FDM method belongs to the most economically accessible among additive methods, thanks to the fact that it is a relatively big time-consuming method of the 3D print, the economic point of view becomes the priority [2]. The frequent requirement is cutting the costs on the 3D print and keeping the demanded quality parameters at the same time as known in case of special parts of high-stressed parts, esp. of ball screws [17, 18]. In terms of the $3 \mathrm{D}$ printing costs, the costs of operating, the production equipment maintenance and material costs are significant $[19,20]$.

\section{LINEAR OPTIMIZATION}

Linear optimization, also called linear programming, enables finding the optimal solution in a range of possible solutions depending on the objective function and limiting conditions. The result may be one or also infinitely many optimal solutions, depending on the objective function and limiting conditions. Both, the objective function and limiting conditions must be in the linear form [21, 22].
In case of application on any production technology, it is necessary to choose appropriate structural variables to find the objective function and limiting conditions based on those structural variables. In terms of influence on FDM technology, we can preliminarily proceed from the temperature that is set for printing thermoplastic $\vartheta\left({ }^{\circ} \mathrm{C}\right)$, the feed speed of the print head $v_{f}(\mathrm{~mm} / \mathrm{s})$ and then from the height of the applied layer $h(\mathrm{~mm})$. They are only the basic parameters of the FDM print having the biggest impact on final quality and production time [13, 23].

The print head temperature influences accessible speed of the print head and partially surface quality. In respect of the first fact, it is more appropriate to include it in limiting conditions and use the layer height and print head speed as structural variables.

In respect of the fact that the dependence of print costs, maximal production capacity within time unit or limiting conditions on those variables is not linear, it is needed to convert all dependences to linear using a logarithmic function. The structural variables then correspond to $\operatorname{logarithms} h$ and $v_{f}$, i.e. $x_{1}=\log (h), x_{2}=\log \left(v_{f}\right)$. Because variables $h$ and $v_{f}$ may go up in values smaller than 10, which leads to negative values in a vector of a right-hand side vector, it is essential to introduce a substitution, when $100 h^{\prime}=h$ and $10 v_{f}^{\prime}=v_{f}$.

As an optimality criterion serves a formula for calculation of minimal costs on the $3 \mathrm{D}$ print $A_{c}[\mathrm{Czech}$ Crowns], optionally minimal production time along with the maximal production capacity within time unit of a device $t_{c}(\mathrm{~min})$.

Limiting conditions may be the limiting of surface roughness, limiting of shape, dimensional accuracy, maximal and minimal material flow through a nozzle, minimal and maximal feed velocity (given by machine parameters), minimal and maximal layer height, required maximal production capacity within time unit, working temperature of material, demanded mechanical qualities and power input of the heating element of the print head. Regarding the fact that there are only two structural variables, both solutions are possible: an arithmetical solution with the use of some mathematic software (e.g. software LiPS [24]) and clear graphic solution. 


\subsection{Criterion of Maximal Production Capacity within Time Unit}

Maximal production capacity within time unit proceeds from a formula of print time.

$t_{c}=\frac{V}{v_{f} \cdot S} \cdot k(\mathrm{~mm})$

where: $t_{c}(\mathrm{~min})$ - final production time, $v_{f}(\mathrm{~mm} / \mathrm{s})$ - feed velocity of the print head, $S\left(\mathrm{~mm}^{2}\right)$ - a section of applied material, $V\left(\mathrm{~mm}^{3}\right)$ - printed object volume, $k(-)$ - Infilling coefficient.
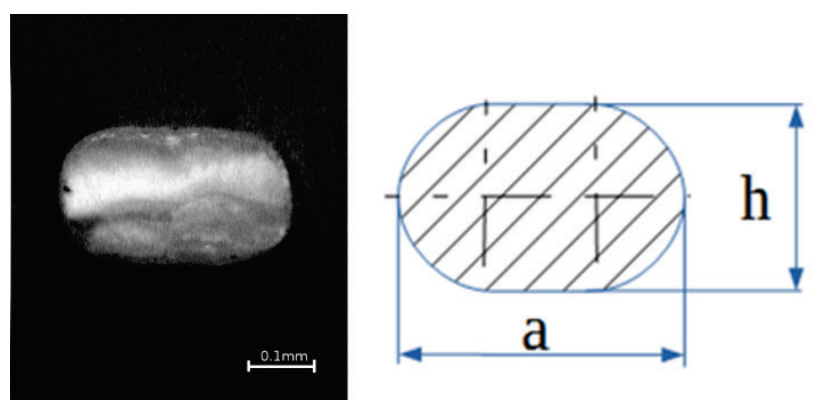

Figure 1 Basic shape of section of applied material during FDM

On the assumption of an appropriate ratio of the layer height to a width of applied material $h / a=1: 1.8$, the area of section is defined by a formula: $S=1.585 \cdot h^{2}$ (see Fig. 1). By supplying and modification of formula (1) with the following forms then the result is:

$$
\begin{aligned}
& t=\frac{\text { Const }}{v_{f} \cdot h^{2}}(\mathrm{~mm}) \\
& \log \left(t_{c}\right)=\log (\text { Const })-\log \left(v_{f}\right)-2 \cdot \log (h)
\end{aligned}
$$

where: $v_{f}(\mathrm{~mm} / \mathrm{s})$ - feed velocity of the print head, $h(\mathrm{~mm})$ - layer height, The Const includes all variables independent of structural variables and does not affect the optimum position of the objective function and does not need to be calculated.

\subsection{Minimal Costs Criterion}

Production costs on the 3D printer depend on the used material and operation costs. Final costs are expressed as follows: [19, 20]

$$
A_{c}=\frac{N_{h}}{60}\left(\frac{V}{v_{f} \cdot 1.385 \cdot h^{2}} \cdot k+t_{v}\right)+\left(N_{m} \cdot m\right)
$$

where: $A_{c}(\mathrm{CZK})$ - production costs expressed in corresponding currency, $V\left(\mathrm{~mm}^{3}\right)$ - a volume of printed component, $N_{h}(\mathrm{CZK} / \mathrm{h})$ - machine operation cost, $k(-)$ constant includes a percentage of the material filling, supports use and loss caused by crossings and acceleration ability of the $3 \mathrm{D}$ print, $t_{v}(\mathrm{~min})$ - secondary time for the print preparation, $N_{m}(\mathrm{CZK} / \mathrm{kg})$ - price per $\mathrm{kg}$ of the material, $m(\mathrm{~kg})$ - weight of the used material.
Secondary time might be regarded as constant towards the layer height or feed velocity, the same as costs on material. After the modification, the following formula is formed and subsequently adjusted to the form (6):

$$
\begin{aligned}
& A_{c}=\frac{K_{1}}{v_{f} \cdot h^{2}}+K_{2} \\
& \log (A)=\log \left(K_{1}\right)-\log \left(v_{f}\right)-2 \cdot \log (h)
\end{aligned}
$$

where: $A(\mathrm{CZK})$ - part of the production costs dependent on the feed velocity and printed layer height $A=A_{c}-K_{2}$, constants $K_{1}$ and $K_{2}$ include all variables independent of structural variables which do not affect the position of optimum of the objective function and do not need to be calculated. The following substitutions are done for application of the linear programming $h=100 h^{\prime}, v_{f}=10 v_{f}^{\prime}$, $x_{1}=\log \left(h^{\prime}\right), x_{2}=\log \left(v f^{\prime}\right), k_{a}=\log \left(A / K_{1}\right)$.

$2 x_{1}+x_{2}-k_{a}=0$

A derived formula shows that the layer height influences the $3 \mathrm{D}$ print process much more than feed velocity. The searching optimum is a maximum with positive parameters on the final function.

\subsection{Limiting Conditions}

Limiting conditions are chosen with regard to workpiece quality and production time. Generally, any amount of limiting conditions may be theoretically included to the process, whereas it is necessary to keep the area of possible solutions $[21,22]$. To obtain the individual dependencies presented in the following chapters, experimental measurements were performed on a specially designed FDM printer using the classical principle of three controlled axes and commercially available print heads E3D v5 and v6 with full metal hot end. The brass nozzles used to allow the use of a wide range of diameters, including customization options. The printer had a heated bed without the use of heated work chamber. The support material was not used when printing. This printer allows you to select a wide range of printing parameters while maintaining high positioning and material feed accuracy $(0,005 \mathrm{~mm})$. The selected restrictive conditions were included primarily to those for which dependency can be determined on the selected structural parameters. Both commercial $\mu$ Print from Stratasys, as well as the more affordable Prusa i3 MK2S, and other devices derived from the Reprap project, were subsequently available to check the functionality.

\subsubsection{Limiting by Allowed Surface Roughness}

One of the significant parameters evaluated on 3D FDM, especially in the case of being used for end-user purposes, is the final surface roughness. From roughness parameters, especially values derived from the maximum height of the profile and arithmetic mean deviation of the profile, $R z$ and $R a$ are used [25]. These values are significantly different on side and top walls. This is especially influenced by the layer height and feed velocity 
of the print head [3]. In case of side wall roughness, the main parameter is the layer height. The principle and the surface profile are displayed in Fig. 2.

From the value $R z$ point of view the maximum theoretic height of profile on the side wall equals the value $a / 2$. Then, the following relation is applied: $h \leq 2 R z$.
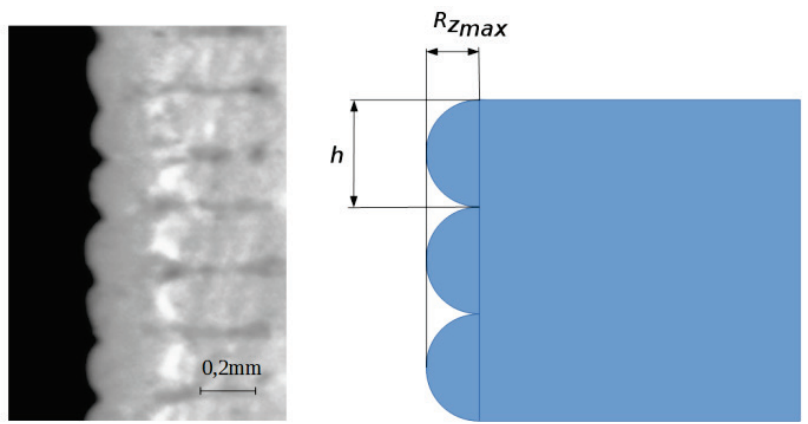

Figure 2 Theoretical roughness on side wall surface.

For the theoretical value, $R a$ at the side wall, the following rule is applied: the middle line lies approximately in the height $0.3927 d h$ (where $d h \approx h$ ) from the edge of the round humps. The area of the circle segment above the middle line is derived from the area of the circle segment and is defined as follows [26]:

$S_{2}=r^{2} \cdot \arccos \frac{(r-h)}{r}-(r-h) \cdot \sqrt{2 h \cdot r-h^{2}}$

After supplying the mentioned variables the theoretical value $R a_{\max }=0.0908 h$. The limiting conditions then correspond to the following formula $h \leq R a_{\max } / 0.0908$.

Usually, the roughness at the side wall is bigger than on front walls. However, in some cases (e.g. print with a very small step) it is appropriate to involve an empirical relationship for the surface roughness gained by experimental measurement of the surface on the front area. The roughness of the front area is given by the layer height, that influences directly the width of the applied material (see Fig. 3), and the print speed along with the working temperature. The reason is also visible in the microscopic pictures of the material surface at various print speeds, see Fig. 4.
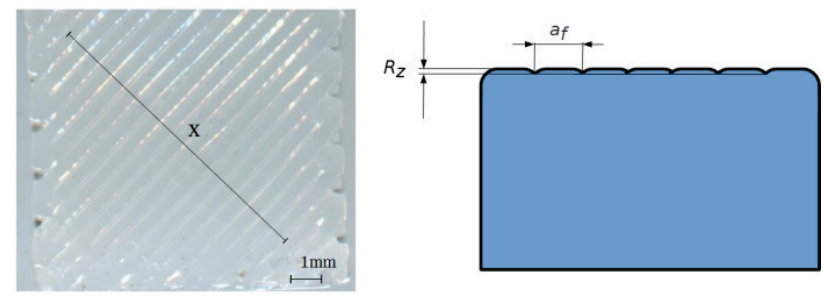

Figure 3 Theoretical roughness of front surface of printed component
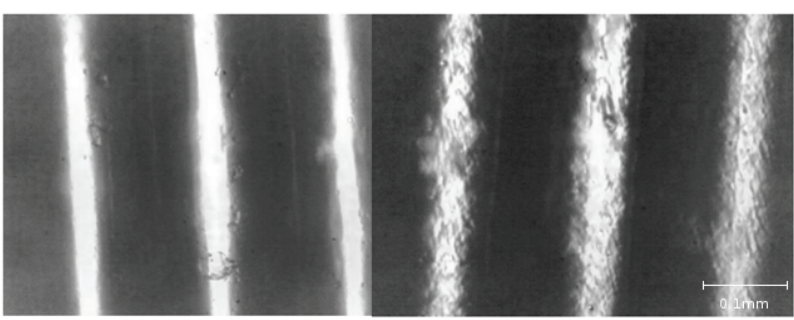

Figure 4 Surface difference of applied material layers for various print speed $30 \mathrm{~mm} / \mathrm{s}$ (left) $-90 \mathrm{~mm} / \mathrm{s}$ (right) ABS $250^{\circ} \mathrm{C}$
Dependence may be evaluated empirically for both feed velocity (see Fig. 5) and layer height. The final dependence is dependent on the used material and a diameter of the used nozzle. Therefore, it is necessary to evaluate it for every single material and the type of printer. For this purpose, the material ABS without any ingredients is used. The material is in a form of a wire of the standard diameter $3 \mathrm{~mm}$ (one of the standards used). The used temperature is $250^{\circ} \mathrm{C}$.

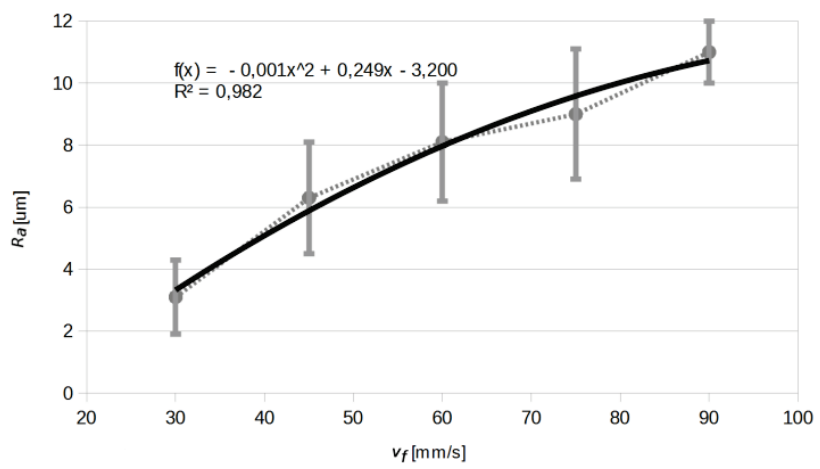

Figure 5 Gained dependence of front surface roughness on feed velocity. Material $\mathrm{ABS}$, temperature $250^{\circ} \mathrm{C}$, nozzle diameter $0.4 \mathrm{~mm}$

The final dependence has the following form $R a=a \cdot f^{2}+b \cdot f+c$, which is exactly the typical quadratic equation. During the equation root solving only one root corresponds to the range of measured values [8] i.e.

$v_{f \max }=\frac{-b+\sqrt{b^{2}-4 a \cdot(c-R a)}}{2 a}$

After supplying gained values the basic shape of the limiting condition is gained:

$v_{f} \leq 124.5-\sqrt{12300-1000 \cdot R a}$

\subsubsection{Limitation by Maximum Deviation of Shape/Dimension}

From the FDM print point of view the problematic issues are especially mistakes emerging during the changes of a print head trajectory or by influence of material shrinkage. Therefore, the biggest inaccuracies emerge in small holes and in areas of sharp edges.

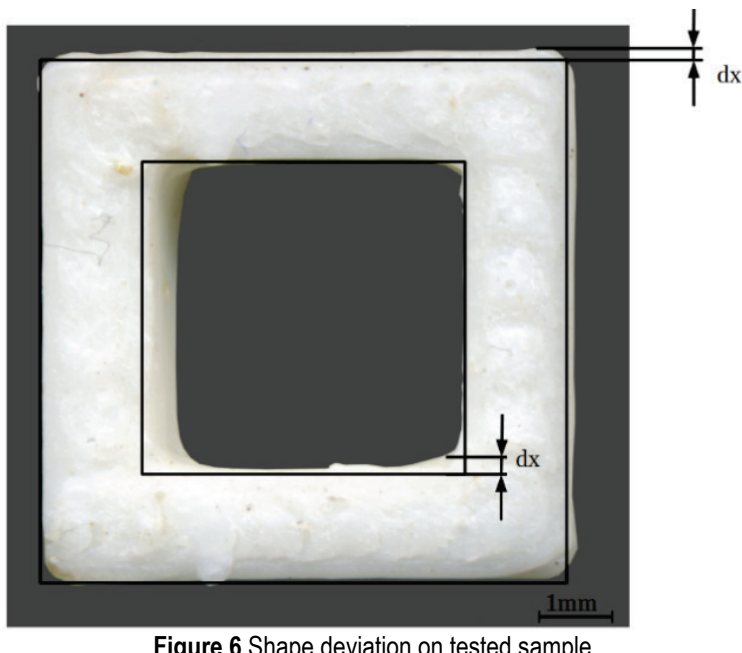

Figure 6 Shape deviation on tested sample 
The final mistake is easily recognisable in Fig. 6. There, the deviation size $d x$ relates to the feed velocity and shape of the formed body (see Fig. 7). A huge impact has especially small holes, i.e. inner shapes with dimension smaller than approximately $10-20$ multiple of the applied material width $(10-20 \cdot a)$. In case of the sharp edge, the material always creates a round edge. Also, with a decreasing curve average, there rises the dimension mistake, when holes have a smaller dimension and outer shapes have a bigger one. When the print speed rises, there does not occur an adequately accurate placing of the material. It is caused by an inertia and viscous liquid state. The next possible issue may be a so-called "seam", which is a connection of a trajectory outline or crossing of the print head through the outline.

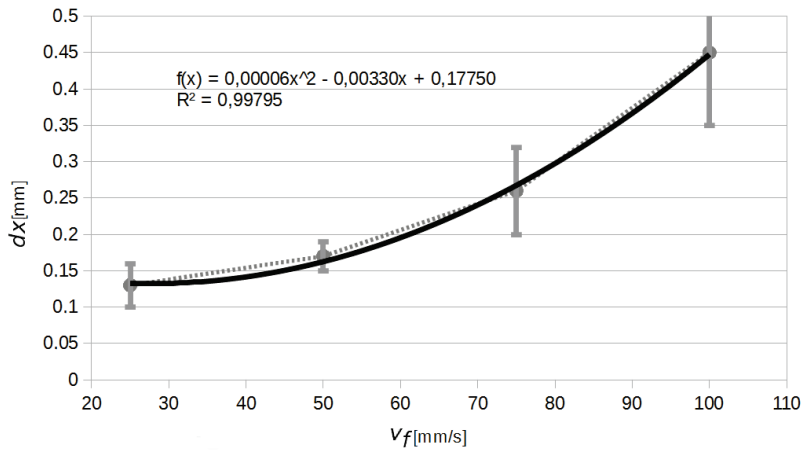

Figure 7 Empirical dependence of shape/dimension deviation gained for ABS material at temperature $250{ }^{\circ} \mathrm{C}$ for range of feed velocities 30 up to $90 \mathrm{~mm} / \mathrm{s}$, sample size $5 \mathrm{~mm}$.

The final dependence has the following form: $d x=a \cdot f^{2}+b \cdot f+c[26]$, which is again the quadratic equation. By supplying figures to the equation for calculation of its roots, whereas the one situated in the measured part is wanted, the following shape is gained:

$v_{f} \leq 27.5-\sqrt{16667 \cdot d x-2202.1}$

\subsubsection{Minimal and Maximal Nozzle Capacity}

This value relates to a nozzle construction, especially with its inside diameter and qualities of the printed material, optionally qualities of the feed mechanism of a plastic wire.

It may vary from decimals $\mathrm{mm}^{3}$ up to dozens or more $\mathrm{mm}^{3}$ for the nozzle of up to $1 \mathrm{~mm}$ diameter. The value influences directly the minimal and maximal print speed. For ABS without any impurities the standard range for nozzle $0.4 \mathrm{~mm}$ is $V_{m}=0.1-20 \mathrm{~mm}^{3} / \mathrm{s}$ on the average. It corresponds approximately to the range of the layer height $0.05-0.33 \mathrm{~mm}$ and feed velocities $5-100 \mathrm{~mm} / \mathrm{s}$. The experiments showed that the better extrusion capacity is usually reached at higher printed temperatures. The final conditions then have the following form:

$v_{f} \leq \frac{4 \cdot V_{m \max }}{\pi \cdot d^{2}}$
$v_{f} \geq \frac{4 \cdot V_{m \min }}{\pi \cdot d^{2}}$

\subsubsection{Minimal and Maximal Feed Velocity}

Similarly, the limit of minimal and maximal feed velocities of the machine may be set; in this case the conditions are given in simple form:

$v_{f} \leq v_{f \max }$

$v_{f} \geq v_{f \min }$

\subsubsection{Minimal and Maximal Layer Height}

The minimal values of the layer height may be both the machine parameter and empirical value given partially by material qualities. The maximal value usually depends on the nozzle diameter. For ABS material, the minimal value of layer height is generally in the range of $0.05-0.1 \mathrm{~mm}$. The maximal layer height is approximately $75 \%$ of the nozzle diameter, whereas the recommended value is $0.5 \mathrm{~d}$.

$$
\begin{aligned}
& h \leq 0.75 \cdot d \\
& h \geq h_{\min }
\end{aligned}
$$

\subsubsection{Minimal Required Production Volume per Hour}

In terms of fulfilling the required minimum production device capacity, we can determine the minimum amount of printed material volume in time. Usually, the value $V_{q}$ in $\mathrm{cm}^{3} / \mathrm{h}$ is given. For this parameter, the conversion is complicated, because it is influenced by feed velocity, layer height, model infilling or physical qualities of the production machine (acceleration, etc.). It may be compensated by defining a constant that varies according to product complicacy and printer type or used material. It is necessary to set the constant for each chosen machine separately. For example, for the tested machine, the constant for the full infilling and acceleration $2,000 \mathrm{~mm} / \mathrm{s}^{2}$ relates to $k_{v}=0.75$.

For the maximal print velocity, the value is $a=1.8 h$, whereas for minimal values and detailed print the value $a$ relates to the nozzle diameter $a=0.5 d$.

The final relation and limiting conditions have the following form:

$$
\begin{aligned}
& V_{q \min }=k_{v} \cdot v_{f} \cdot h \cdot d \cdot 3.6 \\
& v_{f} \cdot h \geq \frac{V_{q \min }}{k_{v} \cdot d \cdot 3.6}
\end{aligned}
$$

\subsubsection{Maximal Extrusion Velocity}

The temperature of the printed material is connected directly with material qualities in the viscose-liquid state [3], which means it also relates to the maximum extrusion velocity $v_{f d}$. This dependence must be set empirically for each chosen material and the nozzle diameter. Also, the feed filament mechanism may have the significant influence.

The curve in Fig. 8 represents the maximum value of the filament feed to the nozzle during which a yield does not occur. For the chosen working temperature [27], the feed limit may be set for the filament and print head by 
other parameters. It must be that the volume of filament delivered to the print head $V_{d}$ corresponds to the volume of material extruded through the nozzle $V_{m}$. The volume change caused by the influence of heat extensity is not considered.

$$
V_{m}=k \cdot h \cdot 1.8 \cdot h \cdot v_{f}
$$

$V_{d}=\frac{\pi \cdot D^{2} \cdot v_{f d}}{240}$

where: $V_{d}\left(\mathrm{~mm}^{3} / \mathrm{s}\right)$ - volume of filament supplied to printhead, $V_{m}\left(\mathrm{~mm}^{3} / \mathrm{s}\right)$ - volume of material coming from nozzle, $D(\mathrm{~mm})$ - filament diameter, $v_{f d}(\mathrm{~mm})$ - maximum extrusion velocity, $k(-)$ coefficient of cross-sectional area.

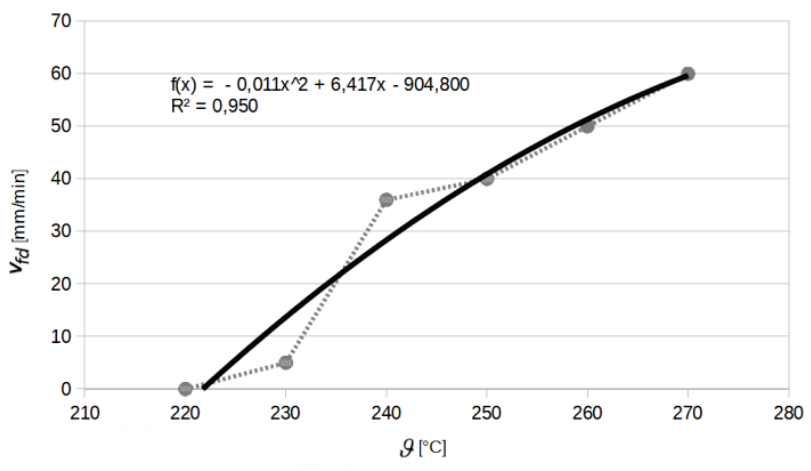

Figure $\mathbf{8}$ Influence of material temperature on maximal filament feed for ABS filament diameter $3 \mathrm{~mm}$

For section corresponding to $a / h=1.8$ coefficient is $k=0.88$. The final limiting condition has the following form:

$$
h^{2} \cdot v_{f} \leq \frac{D^{2} \cdot v_{f d}}{k \cdot 137.5}
$$

\subsubsection{Tensile Strength, Mechanical Properties of Product}

The mechanical qualities of product are influenced by the used temperature of melted material, layer height, or more precisely by the ratio of the nozzle diameter and layer height or the inner structure of material [4 - 11]. The results of the experiments showed that smaller layer height leads usually to better mechanical qualities [29], similarly as the higher temperature of melted material, which has usually more liquid consistence at higher temperatures and easily picks up on the previous layers.

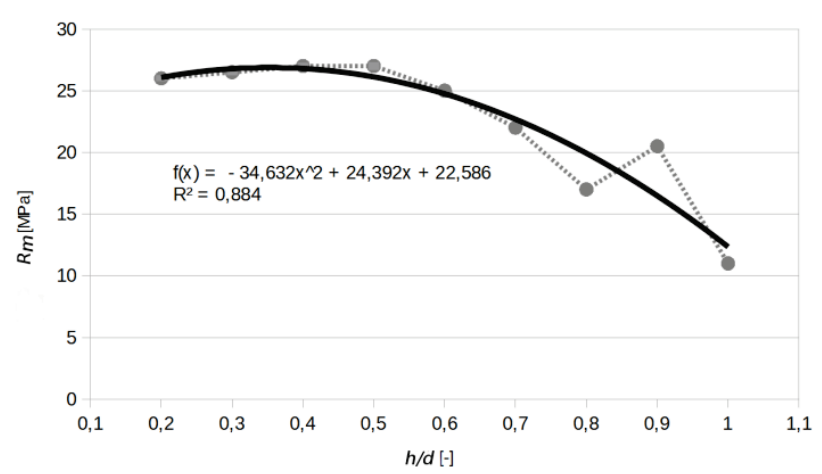

Figure 9 Dependence of tensile strength on ratio of layer height and nozzle diameter, material $A B S, T=250^{\circ} \mathrm{C}, d=0.4 \mathrm{~mm}$.
The bigger contraction and the residual tension at higher printing temperatures act in opposition to this dependence. Those effects are visible especially vertically to applied material direction or individual material layers.

In this case, dependence of the layer height and nozzle diameter indicates the decreasing value of the tensile strength after exceeding the ratio $h / d=0.5$ (see Fig. 9). This dependence may be used as the limit for the layer height based on the required minimal tensile strength. It proceeds from relations for calculation of quadratic equation roots [26].

$$
h \leq \frac{d \cdot\left[-b+\sqrt{b^{2}-4 a \cdot\left(c-R m_{\min }\right)}\right]}{2 a}
$$$$
h \leq 0.141+\sqrt{0.124-0.0046 \cdot R m}
$$

\subsubsection{Heating element Performance Limit}

Energy supplied by a heating element is partially given to the plastics and partially it is distributed to the surroundings. It is caused by radiation and transfer to the cooling medium [28]. Heating element performance limits maximal amount of plastics that may be melted.

The amount of heat distributed to the surroundings differs significantly depending on the construction of a hothead (the FDM print head) and its concrete temperature.
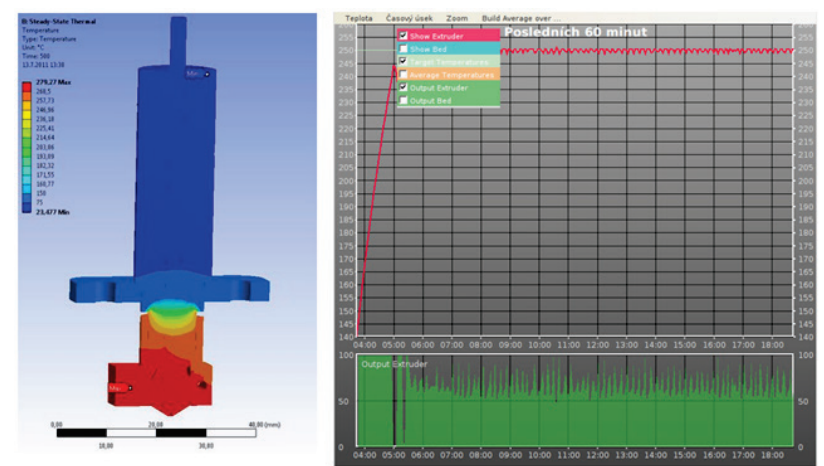

Figure 10 Temperature distribution in FDM print head and required heating element performance

The concrete heat loss figure of a given machine is possible to get by experimental measurement by evaluation of energy distributed to keep the chosen temperature without moving the filament.

The used head has the maximum capacity of the heating element $50 \mathrm{~W}$. For temperature of $250{ }^{\circ} \mathrm{C}$ with active cooling the graph of distributed energy dependent on time is displayed in Fig. 10. It is obvious that for keeping the working temperature $250{ }^{\circ} \mathrm{C}$, it is necessary to use approximately $60 \%$ of distributed energy. The residual energy may be used for melting of the printed material. For heating from $20^{\circ} \mathrm{C}$ up to $250{ }^{\circ} \mathrm{C}$, it means temperature increase of $\Delta \vartheta=230{ }^{\circ} \mathrm{C}$, it is needed to distribute the corresponding heat amount including energy necessary for transition from a solid to viscose-liquid state. The value of the specific heat capacity of ABS material varies linearly in this temperature range from 1400 to $2400 \mathrm{~J} / \mathrm{kg} \cdot \mathrm{K}$ (it corresponds to the medium value for the chosen range $1900 \mathrm{~J} / \mathrm{kgK}$ ). Since it is an amorphous material, there does not occur the real heating point. Our calculation proceeds 
from an average value of the specific heat capacity. Fig. 10 shows that from the total heat amount, there is used only $40 \%$ for the material melting, i.e. $q_{t}=0.4$. Also, it is assumed that the maximum flow through the nozzle is reached in case of bigger layer heights, i.e. at rate of $h / d=0.6$. After supplying the extruded volume of the material per second and a calorimetric equation, the limiting condition for feed velocity and the layer height is gained and has the following form:

$$
h^{2} \cdot v_{f} \leq \frac{0.625 \cdot q_{t} \cdot W_{e}}{\left(10^{-9} \cdot c \cdot \Delta \vartheta \cdot k \cdot \rho\right)}
$$

where: $W_{e}(\mathrm{~W})$ - heater output, $q_{t}(-)$ - coefficient of heat transferred to the material.

\subsection{Linear Programming Application}

For application of the simplex method, the following substitution is introduced: $10 h^{\prime}=h$ and $100 v_{f}^{\prime}=v_{f}$, $\log \left(h^{\prime}\right)=y_{1}, \quad \log \left(v_{f}^{\prime}\right)=y_{2}$. The entry data for linear programming/optimization then have the following form:

$2 y_{1}+y_{2}-c=0$

Limiting Conditions:

$$
\begin{aligned}
& y_{2} \leq a_{1}, y_{2} \leq a_{2}, y_{2} \leq a_{3}, y_{2} \geq a_{4}, y_{2} \leq a_{5}, y_{2} \geq a_{6}, \\
& y_{2} \leq a_{7}, y_{2} \geq a_{8}, \mathrm{y}_{1}+y_{2} \geq a_{9}, 2 \mathrm{y}_{1}+y_{2} \leq a_{10}, \\
& y_{1} \leq a_{11}, 2 \mathrm{y}_{1}+y_{2} \leq a_{12}
\end{aligned}
$$

\section{Concrete Task Application:}

For a concrete solution, the $3 \mathrm{D}$ print method from ABS is applied [2], at temperature $250{ }^{\circ} \mathrm{C}[9,27]$, using the nozzle of $0.4 \mathrm{~mm}$. Other entry values are the following: allowed roughness at the front surface $R a=6.3 \mu \mathrm{m}$; the allowed dimension deviation $d x=0,2 \mathrm{~mm}$; reachable range of material flow through the nozzle $0.1-20 \mathrm{~mm}^{3} / \mathrm{s}$; range of machine feed velocity $5-120 \mathrm{~mm} / \mathrm{s}$; minimal production capacity within time unit $5 \mathrm{~cm}^{3} / \mathrm{h}$; infilling coefficient and print head acceleration $k_{v}=0.75$; required tensile strength $R m=20 \mathrm{MPa}[5,12,13,27]$; heating element capacity $50 \mathrm{~W}$; Infilling coefficient $k=0.95$.

Table 1 Solution of given linear programming task using Simplex >> optimal solution FounD $\gg$ Maximum $=5.49198$

$* * *$ RESULTS - VARIABLES ***

\begin{tabular}{|r|r|r|r||}
\hline variable & value & obj. cost & Reduced cost \\
\hline $\mathrm{x} 1$ & 1.40975 & 2 & 0 \\
\hline $\mathrm{x} 2$ & 2.67247 & 1 & 0 \\
\hline
\end{tabular}

Fig. 11 and Tab. 1 show the found optimal solution. The solution is found by the used application "Linear program solver LiPS v 1.11.1" [24]. The graphic solution shows that from the given criterion point of view any point in the line segment between points $(-0,59021 ; 1,67240)$ and $(-0,52288 ; 1,47525)$ is the optimum. After recalculating $v_{f}=10^{x_{1}}$ and $h=10^{x_{2}} / 100$ or $h=10^{x_{2}}$ (for graphical solution) it corresponds to values $h_{\text {optim }}=$
$0.257 \mathrm{~mm}, v_{f \text { optim }}=47.033 \mathrm{~mm} / \mathrm{s}$ and $h_{\text {optim }}=0.3 \mathrm{~mm}, v_{f \text { optim }}$ $=29.871 \mathrm{~mm} / \mathrm{s}$. In this case, the limits are the maximum speed of extruding through the nozzle at given temperature, the maximal admissible surface roughness and the maximal layer height with respect to the nozzle diameter.

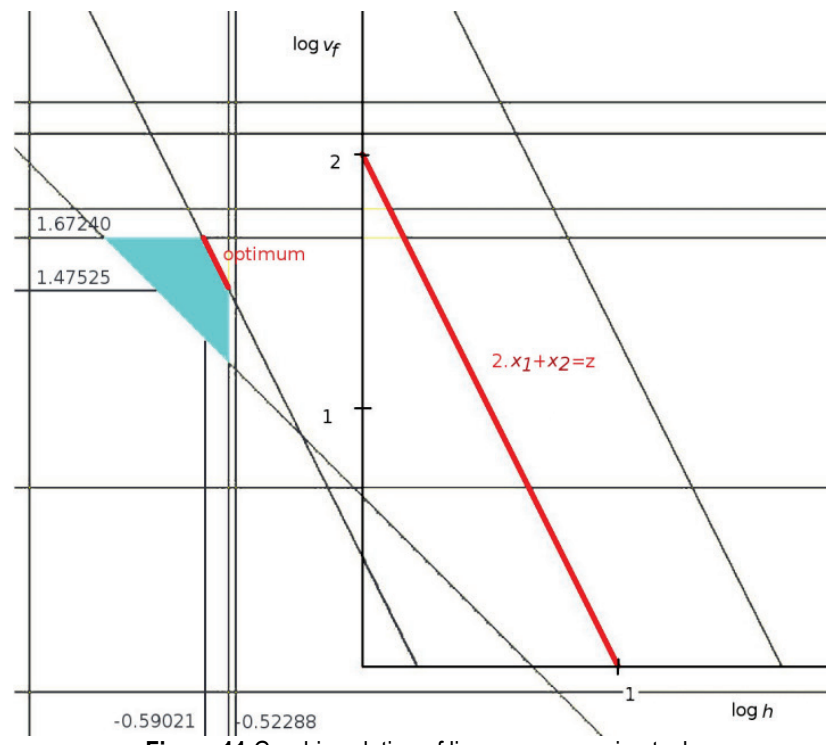

Figure 11 Graphic solution of linear programming task

\section{CONCLUSION}

The application of linear programming appears as functional for finding optimal parameters of the 3D print. The recommended values are real and in expected range. Limits may be set by the machine, material and demanded qualities of the product or economic requirements. Crucial in this case are the surface quality limit, nozzle diameter and nozzle capacity. Small number of structural variables enable using the graphic solution that provides a better overview of optimal parameters and influence of individual limits. A few limits require the relatively time-consuming experimental measurement. This must be done only once for the given material and production equipment. Therefore, it is appropriate to recommend this method in case of using the given material in a long term.

\section{Acknowledgements}

This article was supported and co-financed by the Brno University of Technology, Faculty of Mechanical Engineering, from a specific research 2019, with the grant FSI-S-19-6014 called "Research of perspective production technologies".

\section{REFERENCES}

[1] ASTM, 2012. F2792 - 12e1 Standard Terminology for Additive Manufacturing Technologies. Available from: www.astm.org/Standards/F2792.htm (Accessed: 04.10.2012)

[2] Budmen, I. \& Rotolo, A. (2013). The Book on 3D Printing. 1. Lexington, KY: Create Space. https://doi.org/10.1016/S1350-4789(13)70165-X

[3] Kaveh, M., Badrossamay, M., Foroozmehr, E., \& Hemasian Etefagh, A. (2015). Optimization of the Printing Parameters Affecting Dimensional Accuracy and Internal Cavity for HIPS Material Used in Fused Deposition Modelling 
Processes. Journal of Materials Processing Technology, 226, 280-286. https://doi.org/10.1016/j.jmatprotec.2015.07.012

[4] Khuong, T. L., Zhao, G., Farid, M., Yu, R., Sun, Zhuang, Z., \& Rizwan, M. (2014). Tensile Strength and Flexural Strength Testing of Acrylonitrile Butadiene Styrene (ABS) Materials for Biomimetic Robotic Applications. Journal of Biomimetic, Biomaterials and Biomedical Engineering, 20, 11-21. https://doi.org/10.4028/www.scientific.net/JBBBE.20.11

[5] Nouri, H., Guessasma, S., \& Belhabib, S. (2016). Structural Imperfections in Additive Manufacturing Perceived from the X-ray Micro-Tomography Perspective. Journal of Materials Processing Technology, 234, 113-124. https://doi.org/10.1016/j.jmatprotec.2016.03.019

[6] Pavlic, T., Čikić, A., \& Golubić, S. (2016). Analysis of the Influence of 3D Printing on Hardness of Parts. Tehnicki vjesnik, 23(3), 843-847. https://doi.org/10.17559/TV-20140901165134

[7] Rankouhi, B., Javadpour, S., Delfanian, F., \& Letcher, T. (2016). Failure Analysis and Mechanical Characterization of 3D Printed ABS with Respect to Layer Thickness and Orientation. Journal of Failure Analysis and Prevention, 16(3), 467-481. https://doi.org/10.1007/s11668-016-0113-2

[8] Decuir, F., Phelan, K., \& Hollins, B. C. (2016). Mechanical Strength of 3-D Printed Filaments. The 32 ${ }^{\text {nd }}$ Southern Biomedical Engineering Conference (SBEC). IEEE, 47-48. https://doi.org/10.1109/SBEC.2016.101

[9] Siqueiros, J. G., Schnittker, K., \& Roberson, D. A. (2016). ABS-malleated SEBS Blend as a 3D Printable Material. Virtual and Physical Prototyping, 11(2), 123-131. https://doi.org/10.1080/17452759.2016.1175045

[10] Christiyan, K. G., Chandrasekhar, J. U., \& Venkateswarlu, K. (2016). A Study on the Influence of Process Parameters on the Mechanical Properties of 3D Printed ABS Composite. IOP Conference Series: Materials Science and Engineering, 114(1), 012109. https://doi.org/10.1088/1757-899X/114/1/012109

[11] Faes, M., Ferraris, E., \& Moens, A. D. (2016). Influence of Inter-Layer Cooling time on the Quasi-Static Properties of ABS Components Produced via Fused Deposition Modelling. Procedia CIRP, 42, 748-753. https://doi.org/10.1016/j.procir.2016.02.313

[12] Szykiedans, K., \& Credo, W. (2016). Mechanical Properties of FDM and SLA Low-cost 3-D Prints. Procedia Engineering, 136, 257-262. https://doi.org/10.1016/j.proeng.2016.01.207

[13] Wu, W., Geng, P., Li, G., Zhao, D., Zhang, H. \& Zhao, J. (2015). Influence of Layer Thickness and Raster Angle on the Mechanical Properties of 3D-Printed PEEK and a Comparative Mechanical Study between PEEK and ABS. Materials, 8(9), 5834-5846. https://doi.org/10.3390/ma8095271

[14] Deng, Y., Cao, S.-J., Chen, A., \& Guo, Y. (2016). The Impact of Manufacturing Parameters on Submicron Particle Emissions from a Desktop 3D Printer in the Perspective of Emission Reduction. Building and Environment, 104, 311319. https://doi.org/10.1016/j.buildenv.2016.05.021

[15] Yi, J., Lebouf, R. F., Duling, M. G., Nurkiewicz, T., Chen, B. T., Schwegler-Berry, D., Virji M. A. \& Stefaniak, A. B. (2016). Emission of Particulate Matter from a Desktop Three-dimensional (3D) Printer. Journal of Toxicology and Environmental Health, Part A, 79(11), 453-465. https://doi.org/10.1080/15287394.2016.1166467

[16] Kim, Y., Yoon, C., Ham, S., Park, J., Kim, S., Kwon, O. \& Tsai, P.-J. (2015). Emissions of Nanoparticles and Gaseous Material from 3D Printer Operation. Environmental Science. 49(20), 12044-12053. https://doi.org/10.1021/acs.est.5b02805

[17] Pokorny, Z., Barborak, O., \& Hruby, V. (2012). Characteristics of Plasma nitride layers in deep Holes. Kovové Mater, 50(3), 209-212. https://doi.org/10.4149/km_2012_3_209. ISSN 0023-432X
[18] Pokorny, Z., Dobrocky, D., Kadlec, J., \& Studeny, Z. (2018). Influence of alloying elements on gas nitriding process of high-stressed machine parts of weapons. Kovové Mater., 56(2), 97-103. https://doi.org/10.4149/km_2018_2_97

[19] Schröder, M., Falk, B., \& Schmitt, R. (2015). Evaluation of Cost Structures of Additive Manufacturing Processes Using a New Business Model. Procedia CIRP: The $7^{\text {th }}$ Industrial Product-Service Systems Conference - PSS, industry transformation for sustainability and business. Elsevier B. V., 30, 311-316. https://doi.org/10.1016/j.procir.2015.02.144

[20] Baumers, M., Dickens, P., Tuck, C. \& Hague, R. (2016). The Cost of Additive Manufacturing: Machine Productivity, Economies of Scale and Technology-push. Technological Forecasting and Social Change, 102, 193-201. https://doi.org/10.1016/j.techfore.2015.02.015.

[21] Kolman, B. \& Beck, R. E. (1995). Elementary Linear Programming with Applications. $2^{\text {nd }}$ ed. San Diego: Academic Press, c1995, XXII, 449 p. Computer science and scientific computing.

[22] Gass, S. I. (2003). Linear Programming: Methods and Applications. $5^{\text {th }}$ ed. New York: Dover Publications, XI, 532 p.

[23] Tymrak, B. M., Kreiger, M., \& Pearce, J. M. (2014). Mechanical Properties of Components Fabricated with Open-source 3-D Printers under Realistic Environmental Conditions. Materials, 58, 242-246. https://doi.org/10.1016/j.matdes.2014.02.038

[24] LiPS: Linear Program Solver. Source Forge [online]. La Jolla, CA 92038: Slashdot Media, 2013 [cit. 2016-06-29]. Available at: http://lipside.sourceforge.net/

[25] ISO 468:1993. Surface Roughness. Parameters, Their Values and General Rules for Specifying Requirements. 1. Prague: Czech Normalisation Institute, 8 p. Available at: http://csnonline.unmz.cz/

[26] (2015). Mathematical, Physical and Chemical Tabs for High Schools. 1. Praha: Otto Publishing Company, Ltd.

[27] FDM Material Properties [online]. Usti nad Labem: Materialise, 2012 [cit. 2016-07-01]. Available at: http://www.materialise.cz/sites/default/files/public/AMS/da tasheets_e_fdm.pdf

[28] Jerez-Mesa, R., Travieso-Rodriguez, J. A., Corbella, X., Busqué, R., \& Gomez-Gras, G. (2016). Finite Element Analysis of the Thermal Behaviour of a RepRap 3D Printer Liquefier. Mechatronics, 36, 119-126. https://doi.org/10.1016/j.mechatronics.2016.04.007

[29] Popescu, D., Aurelian Z., Catalin A., Florin B., \& Rodica M. (2018). FDM process parameters influence over the mechanical properties of polymer specimens: A review: A review. Polymer Testing, 69, 157-166. https://doi.org/10.1016/j.polymertesting.2018.05.020

\section{Contact information:}

\section{Oskar ZEMČíK, PhD, MSc}

Brno University of Technology,

Faculty of Mechanical Engineering,

Institute of Manufacturing Technology,

Technická 2896/2, 61669 Brno, Czech Republic

zemcik.o@fme.vutbr.cz

Josef SEDLÁK, Assoc. Prof., PhD, MSc Brno University of Technology,

Faculty of Mechanical Engineering, Institute of Manufacturing Technology, Technická 2896/2, 61669 Brno, Czech Republic sedlak@fme.vutbr.cz 